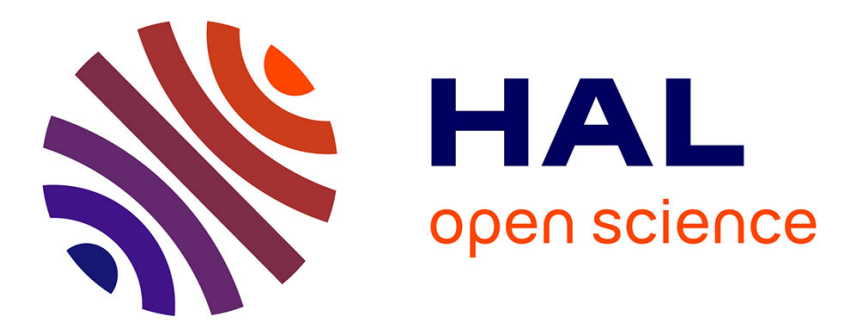

\title{
Plant Lectins are Novel Toll-Like Receptor Agonists
}

John Unitt, David Hornigold

\section{To cite this version:}

John Unitt, David Hornigold. Plant Lectins are Novel Toll-Like Receptor Agonists. Biochemical Pharmacology, 2011, 10.1016/j.bcp.2011.03.010 . hal-00693837

\section{HAL Id: hal-00693837 https://hal.science/hal-00693837}

Submitted on 3 May 2012

HAL is a multi-disciplinary open access archive for the deposit and dissemination of scientific research documents, whether they are published or not. The documents may come from teaching and research institutions in France or abroad, or from public or private research centers.
L'archive ouverte pluridisciplinaire HAL, est destinée au dépôt et à la diffusion de documents scientifiques de niveau recherche, publiés ou non, émanant des établissements d'enseignement et de recherche français ou étrangers, des laboratoires publics ou privés. 


\section{Accepted Manuscript}

Title: Plant Lectins are Novel Toll-Like Receptor Agonists

Authors: John Unitt, David Hornigold

PII:

S0006-2952(11)00177-8

DOI: doi:10.1016/j.bcp.2011.03.010

Reference: $\quad$ BCP 10850

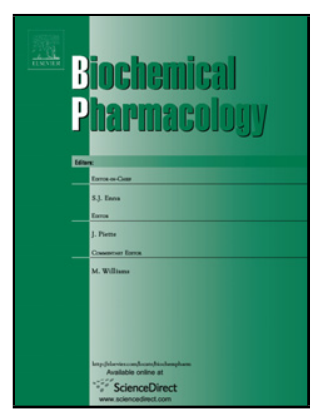

To appear in: $\quad B C P$

Received date: $\quad 3-2-2011$

Revised date: $\quad$ 8-3-2011

Accepted date: $\quad$ 9-3-2011

Please cite this article as: Unitt J, Hornigold D, Plant Lectins are Novel Toll-Like Receptor Agonists, Biochemical Pharmacology (2010), doi:10.1016/j.bcp.2011.03.010

This is a PDF file of an unedited manuscript that has been accepted for publication. As a service to our customers we are providing this early version of the manuscript. The manuscript will undergo copyediting, typesetting, and review of the resulting proof before it is published in its final form. Please note that during the production process errors may be discovered which could affect the content, and all legal disclaimers that apply to the journal pertain. 


\section{Plant Lectins are Novel Toll-Like Receptor Agonists}

John Unitt and David Hornigold

Corresponding author

Dr J F Unitt

*AstraZeneca R\&D Charnwood, Bioscience, Bakewell Road, Loughborough LE11 $5 \mathrm{RH}, \mathrm{UK}$

john.unitt@astrazeneca.com

Tel. +44 (0)1509645445

Fax $+44(0) 1509645557$

*Present address

Classification

(5) Inflammation and Immunopharmacology 


\section{Abstract}

The T cell mitogen and plant glycoprotein, phytohaemagglutinin (PHA), is commonly used to stimulate peripheral blood mononuclear cell (PBMC) preparations to produce IL-2, IL-5, GM-CSF and IFN- $\gamma$ and so provide an assay to detect immunosuppressants like FK506 and anti-inflammatories such as PDE IV inhibitors. During the early discovery of novel TLR agonists for the treatment of asthma we initially showed that PHA-L is a specific human TLR4 agonist, devoid of effects on equivalent TLR4 null cells. This TLR4 agonism was not due to LPS contamination of PHA-L, as polymyxin B was ineffective and unlike PHA-L, LPS did not stimulate TLR5 or TLR2/6. Also this specific PHA-L agonism of TLR4 was shown for different PHA forms, for example, PHA-P.

This TLR lectin pharmacology finding was further explored by testing a broader panel of plant lectin representatives for agonism against a suite of hrTLR cell reporter assays $(2 / 6,3,4,5,7,8$ and 9$)$.

Soyabean agglutinin (SBA), concanavalin $\mathrm{A}$ (ConA) and PHA lectin family members only stimulated extracellular TLRs $(2 / 6,4$ and 5$)$ probably due to lack of intracellular access, whilst other lectins were either pan-active (WGA) or inactive (AIL). Interestingly SBA only stimulated TLR4, ConA, TLR2/6 and PHA-L, TLR2/6, 4 and 5. As each lectin family exhibits different sugar ligand specificity for interaction, these results suggest that the pharmacology of this TLR agonism is encoded by the lectin's carbohydrate recognition motifs and the appropriate surface presentation of these motifs on different TLRs. 
Key words

Toll-like receptors

Plant lectins

LPS

Phytohaemagglutinin

Reporter assay

Abbreviations

LPS, lipopolysaccharide

NF-kB, nuclear factor $\mathrm{kB}$

$\mathrm{PMB}$, polymyxin B

ConA, concanavalin A from Canavalia ensiformis (Jack Bean)

SBA, soybean agglutinin from Glycine max (Soybean)

PHA, phytohaemagglutinin from Phaseolus vulgaris (Red kidney bean)

PHA-L, tetramer of $L$ isolectin subunits (i.e. $L_{4}$ )

PHA-P, tetramer of $L$ and $E$ isolectin subunits mixtures (i.e. $L_{1} E_{3}, L_{2} E_{2}, L_{3} E, E_{4}, L_{4}$ )

WGA, wheat germ agglutinin from Triticum vulgaris

AIL, lectin from Artocarpus integrifolia (Jacalin)

PNA, peanut agglutinin from Arachis hypogaea

IA, intrinsic activity

$\mathrm{pEC}_{50},-\log _{10}\left\{\mathrm{EC}_{50}[\mathrm{LPS}\right.$ or lectin] $(\mathrm{g} / \mathrm{ml})\}$ or $-\log _{10}\left\{\mathrm{EC}_{50}\right.$ [Compound] (M)\}

NA, not active 


\section{Introduction}

Lectins represent a very large family of glycoproteins $(>100)$ that specifically bind to mono- or oligosaccharides with varying degrees of valency. They are oligomeric and exhibit broad structural diversity with varying molecular size $(60-400 \mathrm{kDa})$, complexity and shape. Each lectin polypeptide contains many molecular domains, one of which is the carbohydrate recognition domain, responsible for their ability to recognize and interact with specific glycoconjugates.

Lectins are universally expressed and have been shown to function in animals, plants, and microorganisms as cell and molecular recognition proteins [1]. Not only do lectins bind to cells via glycoprotein recognition, but they also facilitate communication between cells and molecules, for example, lectins are critical to host defense in plants, as well as regulation of glycoprotein biosynthesis and cell migration in animals.

Seminal studies into the agglutination effects of plant lectins on animal cells began in 1888 by Stillmark, leading to increased interest and the eventual application of these proteins for blood typing, malignant cell surface glycoprotein architecture and understanding oligosaccharide protein interactions; for review see [2]. However it wasn't until 1960 that Nowell et al. [3] showed that PHA was a potent lymphocyte mitogen. Subsequently the specific interaction recognition site for this PHA-driven lymphocyte activation was identified as $\mathrm{Ti}$, a protein intimately associated with the $\mathrm{T}$ cell receptor (TCR):CD3 complex [4]. 
This ability of PHA to stimulate specific cell types subsequently provided a readily available array of in vitro cell functional assays to study biological systems ranging from mitogenicity to pro-inflammatory cytokine production. As these assays are both routine and reliable, they have been and still are used by the pharmaceutical industry as definitive secondary assays to identity and confirm novel anti-inflammatory and immunomodulatory agents, such as the emerging importance of TLR modulators. This interest in modulating TLR function, especially agonism, has materialized over the last 10 years and is an area potentially rich in therapeutic opportunities to provide novel treatments for a range of different diseases such as cancer, rheumatoid arthritis and SLE [5].

Although TLRs are able to recognize a broad spectrum of structurally diverse ligands ranging from small molecules and polynucleotides to lipopeptides from synthetic, host and pathogen sources, there is surprisingly little literature on the direct interaction of TLRs with lectins [6,7]. For example, TLR4 has been shown to respond to a growing catalogue of structurally diverse ligands ranging from the seminal ligand, LPS to taxol [8] and hyaluronan [9]. Interestingly TLR4 requires specific $\mathrm{N}$-glycosylation to function as an LPS receptor in concert with MD-2 [10], yet it is not known whether carbohydrate recognition ligands such as plant lectins can act as TLR4 ligands. With this in mind we investigated the effect of plant lectins on a panel of hrTLR NF-kB reporter cell assays and clearly demonstrate in this paper that PHA-L and other lectins are able to act as specific ligands for certain TLRs. 


\section{Materials and Methods}

\subsection{Reagents}

Plant lectins were purchased from Sigma-Aldrich (St. Louis, MO, USA) and Roche Diagnostics Ltd. (Burgess Hill, UK). SEAP reporter cell line, Zeocin ${ }^{\mathrm{TM}}$, Blasticidin S HCl, Hygromycin B solution, Pam3Cys, Poly(I:C), flagellin, CpG-B, 3M 002 (CL075), R-848 and Ultrapure LPS (0111:B4) were obtained from InvivoGen (San Diego, CA, USA). DDAO Phosphate was from Molecular Probes (Invitrogen, Paisley, UK). Cryopreserved purified Clonetics ${ }^{\circledR}$ CD14+ human monocytes were supplied by Lonza UK Ltd., Cambridge, UK. For the TNFa fluorescence- linked immunosorbent assay (FLISA), hrTNFa, anti-human TNFa monoclonal antibody, anti-TNFa biotinylated antibody were from R\&D Systems (Abingdon, UK), Spherotech goat antimouse beads from Saxon (Kelso, UK) and ZyMax grade Streptavidin-Alexa647 from Invitrogen (Paisley, UK). All other reagents were purchased from Sigma-Aldrich (St. Louis, MO, USA).

\subsection{Cell Culture}

The most common variant sequence of each human TLR was determined and then cloned into the mammalian cell expression vector pUNO (InvivoGen) and transfected into the HEK (human embryonic kidney) secreted alkaline phosphatase (SEAP) reporter cell-line. This SEAP reporter cell already expressed the pNiFty2 vector (InvivoGen) for NF-KB inducible control of the SEAP reporter gene via the endothelial cell-leukocyte adhesion molecule 1 promoter. A single clone for each TLR reporter 
cell line was selected on the basis of giving an optimal response to the cognate TLR agonist. The TLR8/4 chimera was made by fusing the endosomal domain of TLR8 with the transmembrane and intracellular domain of TLR4 at a conserved Thr-Cys site present just into the endosomal TLR8 domain, see [11] for further details.

Cells were cultured in Dulbecco's Modified Eagle's Medium (DMEM) containing 10\% (v/v) FBS, 2 mM L-glutamine, $100 \mu \mathrm{g} / \mathrm{ml}^{\mathrm{ml}}$ Zeocin $^{\mathrm{TM}}, 50 \mu \mathrm{g} / \mathrm{ml}$ Hygromycin B and 10 $\mu \mathrm{g} / \mathrm{ml}$ Blasticidin S and maintained at $37^{\circ} \mathrm{C}$ in a $5 \%(\mathrm{v} / \mathrm{v}) \mathrm{CO}_{2} /$ air environment with $95 \%$ humidity.

\subsection{Cell Reporter SEAP Assay}

Cells were incubated at $1.5 \times 10^{6} / \mathrm{ml}$ in DMEM supplemented with $1 \%(\mathrm{v} / \mathrm{v})$ foetal bovine serum (FBS), $2 \mathrm{mM}$ glutamine, $100 \mathrm{U} / \mathrm{ml}$ penicillin, and $100 \mathrm{\mu g} / \mathrm{ml}$ streptomycin prior to stimulation with lectins/LPS/TLR standard agonists for 20 hours at $37^{\circ} \mathrm{C}$ in a $5 \%(\mathrm{v} / \mathrm{v}) \mathrm{CO}_{2} /$ air environment, $95 \%$ humidity. Measurement of SEAP cell reporter activity was performed as described by InvivoGen [12].

\subsection{Monocyte TNF $\alpha$ Production Assay}

Cryopreserved human monocyte preparations were thawed and incubated at $1 \times 10^{6}$ cells $/ \mathrm{ml}$ in DMEM supplemented with $10 \%$ (v/v) FBS, $2 \mathrm{mM}$ glutamine, $100 \mathrm{U} / \mathrm{ml}$ penicillin, and $100 \mu \mathrm{g} / \mathrm{ml}$ streptomycin prior to stimulation with lectins/LPS for 20 hours at $37^{\circ} \mathrm{C}$ in a $5 \%(\mathrm{v} / \mathrm{v}) \mathrm{CO}_{2} /$ air environment, $95 \%$ humidity. TNFa in the media was measured using a FLISA [13]. 


\section{Results}

\subsection{PHA specifically activates TLR4}

Our results showed that different forms of PHA (i.e. PHA-L and PHA-P) stimulated TLR4 NF-KB reporter activity with a similar potency, but lower than that of LPS (see Fig. 1). The absolute potency of PHA-L (>95\% pure, Mr $115 \mathrm{kDa}$ ) measured was 7 $\mathrm{nM}\left(\mathrm{pEC}_{50} 8.2\right)$ with a maximal efficacy $\sim 80 \%$ that of LPS. PHA-P was more efficacious than PHA-L suggesting that $E$ isolectin components present in PHA-P drive the greater stimulation; further work using PHA-E (i.e. $E_{4}$ ) would help to confirm this hypothesis.

\section{[Insert Figure 1]}

The TLR4 specificity of this finding for PHA was shown by the inactivity of the PHA forms in stimulating reporter activity in an equivalent TLR null assay in contrast to TNFa, which worked equivalently in all HEK TLR reporter assays due to coupling of endogenous TNF $\alpha \mathrm{R} 1$ activation to the $\mathrm{NF}-\kappa \mathrm{B}$ reporter. As expected, LPS only worked in the TLR4 expressing cell line and not in the parental equivalent (see Table 1). Interestingly, although the TLR4 reporter $\mathrm{pEC}_{50}$ values for the different PHAs were the same, the intrinsic activities were significantly different with the following ranking: PHA-P > PHA-L.

\section{[Insert Table 1]}

A major concern was that PHA preparations from plant extracts may be contaminated with LPS, leading to misinterpretation of a direct TLR4 activation by PHA itself. To address this we treated our PHA preparations with polymyxin B (PMB), a well established technique to remove LPS and so eliminate the possibility 
of LPS contamination interfering with the results [14]. As Table 2 clearly demonstrates, PMB inactivated LPS as expected, but had no effect on the PHA-L TLR4 response, suggesting no LPS contamination in the lectin preparation; this was the case for all TLR4 active lectins (data not shown). To strengthen this conclusion further we showed that PHA-L equivalently stimulated TLR2/6 as well as TLR4, yet LPS only stimulated TLR4 (see Table 3) hence implying that PHA-L behaves differently to LPS. Together these results suggest that PHA-L has no significant LPS contamination and that agonism of both TLR2/6 and TLR4 is a consequence of PHA$L$ itself.

\section{[Insert Table 2 and 3]}

\subsection{Plant lectins exhibit varied TLR agonist pharmacology}

Based on the identification of PHA-L as a TLR4 agonist, we thought it would be interesting to explore this finding further by examining the effects of different lectins on a range of TLRs. Therefore we selected a small representative set of lectins with different oligosaccharide recognition motifs and tested them for agonism using a suite of human TLR NF-KB reporter assays run in comparison to the cognate native ligand for each receptor. The data summarised in Table 4 shows a number of interesting findings, first of all, none of the lectins stimulated parental cell reporter activity and secondly they generally stimulated external $(2 / 6,4$ and 5) compared with internal TLRs $(3,7,8$ and 9). This indicates that lectins are unable to activate NF-KB per se and that extracellular TLRs are more amenable to lectin interaction than endosomal ones.

[Insert Table 4] 
Intriguingly PHA-L significantly stimulated all the extracellular TLRs, yet other lectins like SBA and PNA, only activated TLR4. In contrast AIL was inactive in all the cell reporter assays tested, whilst WGA was the most promiscuous in that it activated all the TLR assays except 3 and 4 . ConA only activated the TLR2/6 cell assay. Overall the patterns of TLR activation by different lectins varied from complete inactivity (i.e. AIL) to selectivity for one TLR (e.g. SBA) to near pan stimulation across the board by WGA. From a TLR perspective, all TLRs were stimulated by at least one lectin except for TLR3, which only showed activation due to its cognate polynucleotide agonist, poly(l:C).

\subsection{PHA-L cannot activate intracellular TLR8 even when expressed on the cell surface}

One surprising finding was that only WGA activated cells expressing certain endosomal TLRs, i.e. 7, 8 and 9 . Interestingly some lectins are able to enter cells and WGA has been shown to accumulate in acidic endosomes, the same locations as the intracellular TLRs [15]. This suggests that WGA is able to access these TLRs to potentially activate them; further work using labelled WGA would be required to confirm this. The activation of intracellular TLRs by WGA was selective in that TLR3 was not activated, suggesting a specific TLR interaction rather than a gross effect on endosomal environment.

To explore the effect of TLR cellular location on activation by lectins, we tested a lectin that was unable to stimulate an intracellular TLR, for example PHA-L on TLR8 
(see table 4), for agonism of chimaeric TLR8/4 that consisted of an extracellular TLR8 domain fused to an intracellular TLR4 domain to ensure plasma membrane receptor expression. Table 5 shows that TLR8/4 exhibits the same pharmacology for the standard TLR8 agonist (3M 002) as the normal endosomally expressed TLR8 and was unresponsive to LPS. PHA-L exhibited no agonism of TLR8/4 or TLR8, suggesting it was unable to activate TLR8 even when the receptor was more accessible on the cell surface, suggesting that even if PHA-L did gain access to the cytosol it would still be unable to activate the receptor.

\section{[Insert Table 5]}

\subsection{PHA-L is an agonist of native extracellular TLR function}

At this stage we had clearly demonstrated that some plant lectins are TLR agonists using a suite of recombinant receptor NF-KB cell reporter assays, but would this finding translate directly into native, primary cell function?

To answer this question we focused on our most potent interaction, PHA-L with TLR4. PHA-L is a potent T cell mitogen, so we were unable to use T-cell containing preparations like PBMCs as this would make interpretation very difficult; indeed mitogen (PHA and OKT3) driven TNFa production by PBMCs is known to be dependent on T-cell activation [16]. Therefore we used purified human monocytes and measured PHA-L-driven TNFa production as this cell type is known to express functional TLR2, 4 and 5 receptors and to predominantly produce TNFa in response to ligands to these TLRs, like lipoteichoic acid (TLR2), LPS (TLR4) and flagellin (TLR5) [17]. As expected LPS was a highly potent and efficacious stimulant of TNFa 
production, whilst PHA-L was significantly weaker (see Table 6), such that the overall ranking of potency and efficacy of ligands between reporter and monocyte assay was conserved.

[Insert Table 6] 


\section{Discussion}

Plant lectins are routinely used in general biochemistry, cell biology and immunology, as well as for diagnostic, immunomodulatory and therapeutic purposes, especially in oncology and infection. Indeed companies have pursued recombinant lectin-based approaches for treating cancer, for example, lectin ATL-104 (Alizyme) for mucositis and CY-503 for metastatic melanoma (Cytavis) are currently in Phase II. The two main challenges for lectin-based drugs are selectivity and cytotoxicity, as well as a greater understanding of their therapeutic mechanism of action [18].

In going some way to deepen our immunomodulatory knowledge of lectin selectivity and mechanism, we report the novel finding that certain plant lectins exhibit specific patterns of human TLR stimulation, suggesting that the innate immune system can detect and respond to certain lectins (see Fig 1. and Table 4). The specificity of this TLR stimulation was shown by the inactivity of PHA lectins in a control cell assay in which no TLR was expressed (see Table 1) and that the stimulation of TLR4 was not due to LPS contaminating the lectin preparations. Concentration-response curves had similar slopes to LPS, suggesting a similar mode of agonism and receptor interaction; indeed it would be interesting to see how combinations of LPS and PHA$\mathrm{L}$ affected the TLR4 activation profile. One likely explanation for this pattern of lectin TLR pharmacology is that each TLR-type is decorated differently with carbohydrate motifs such that interaction with an appropriate lectin leads to selective receptor activation. Indeed lectins could potentially work through promotion of TLR dimerisation in a similar manner to PHA promotion of TCR-CD3 cross-linking required for polyclonal T cell activation [19]. 
The specificity of lectin activation of TLRs was further strengthened by the finding that all lectins tested showed no activity in the parental line so precluding activation of endogenous receptors linked to NF-kB, like TNF $\alpha-R 1$. Importantly differences in agonist response between TLR assays assumes comparable levels of TLR expression and gene reporter coupling in each assay; this assumption was supported by a similar absolute efficacy for TNFa in all cell lines and a robust response to each TLR's cognate agonist. Using the established oligosaccharide recognition properties of the different lectins an emerging relationship between recognition motifs and TLR response patterns can be identified (see Table 4). Mannose-binding lectin ConA preferred TLR2/6, a finding that could be further strengthened by testing other members of this lectin class such as lentil lectin (lens culinaris) and snowdrop lectin (galanthus nivalis). In contrast galactose/Nacetylgalactosamine preferring lectins PNA and SBA only stimulated TLR4 with maximal efficacy better than LPS, yet AlL, a similarly lectin, was surprisingly inactive against TLR4. As PNA, SBA and AIL all bind to glycoproteins via a similar oligosaccharide motif, the TLR4 inactivity of AIL would suggest that AIL may bind TLR4 in a similar manner to PNA and SBA, and therefore may be likely to behave as an antagonist. The broader effects on the TLR panel of the only sialic acid recognizing lectin tested, WGA, suggest that SA expression may be common to most TLRs and also provide access to activate intracellular TLRs. Indeed this profiling exercise could be expanded to include more members of the plant lectin family to both consolidate and expand the current limited picture of lectin TLR pharmacology, for example, testing members of the remaining major lectin families, 
i.e. fucose (Ulex europaeus agglutinin) and $\mathrm{N}$-acetylneuraminic acid (Elderberry lectin) recognition motifs.

TLR4 is a complex of three proteins, CD14/LBP, MD2 and TLR4, all required for LPS to signal $[20,21]$. We do not know which of these proteins or combination of proteins are required for PHA-L to function, but future co-expression studies would help to identify the receptor component(s) required. Furthermore, the nature of the molecular interaction between PHA-L and TLR4 could be explored in greater detail and more directly by using fluorescently labelled lectins. This approach could lead to the identification, specificity, location and kinetics of this interaction and potentially track the movement of any PHA-TLR complexes. Moreover fluorescently labeled lectins have been used effectively to detect and sort cell types as well as define kinetics [22], so by designing a labeled lectin TLR binding assay a new avenue into screening for small molecules that interact with TLRs can be pursued. Other standard lectin biology-based tools could also be applied to gain greater understanding of this lectin-TLR activation, for example, demonstrate blockade of lectin activation using known cognate oligosaccharides and/or modulation of protein glycosylation using swainsonine [23].

The 20-fold higher PHA-L potency and 4-fold higher efficacy observed in recombinant TLR4 compared with monocyte stimulation (see Table 6) may be due to a variety of factors and certainly warrants further exploration. Importantly monocytes produce the most TNFa in response to stimulation of either TLR2/6, 4 or 5 , meaning that the TLR(s) that PHA-L stimulates cannot be specifically defined at this stage. Indeed the lack of selective antagonists of TLR2/6, 4 and 5 precluded any further 
work in clearly identifying the native TLR(s) that PHA-L may stimulate, but testing of more individual TLR specific lectins, like ConA for TLR2/6 (see Table 4), may help to further define native TLR activation by lectins. Other monocytic receptors known to produce TNFa on stimulation are for interferon- $\gamma$ and granulocyte macrophage colony stimulating factor, but both maximally produce 10 -fold less TNF $\alpha$ compared with TLR2, 4 or 5 [17], so it's less likely that PHA-L is engaging these receptors. Although LPS serves as a useful standard to measure assay performance and comparison with the reporter assays, its structure, valency, mechanism and physicochemical profile is very different to that of a lectin, so precluding a direct agonist comparison. Indeed LPS is some 100 -fold more potent in the monocyte TNF $\alpha$ assay in keeping with previous reports of LPS TNFa induction potencies $\mathrm{pEC}_{50}$ 8-10 [24]. This difference in agonism seen between the two assays is not easily explained without further investigation centered on the major determinants of classical receptor agonism; i.e. (a) receptor occupancy, (b) efficacy and (c) receptor number. One particular consideration for lectins is that there may be cell system differences in surface expression of oligosaccharides on TLR4, such that the recombinant receptor assay is a more sensitive to lectin stimulation than a native receptor functional assay. A comparison of the known potencies for PHA-L (see Table 7) clearly shows the relatively low affinity of the monocytic TNFa response compared with cell binding [25] or PBMC stimulation [26]. Finally with the advent of agonist texture in receptor function [27] it may be that PHA-L stimulates a different pattern of cytokines and/or cell functions to LPS and so a broader assessment of cell functions should be investigated.

\section{[Insert Table 7]}


In conclusion the action of PHA-L as a stimulant in classical PBMC cell functional assays is predominantly due to its more potent, efficacious and well known action as a T-cell stimulant $\left(\mathrm{pEC}_{50} \sim 6\right)$ rather than as a extracellular TLR agonist $\left(\mathrm{pEC}_{50} 4.6\right)$; see Table 7 for comparison. Whether lectin activation of TLRs, like TCR, occurs through a similar dimerisation or cross-linking process remains to be discovered. Our observations so far provide a basic characterization of TLR-lectin pharmacology and further work remains to be done on extending, exploring and applying these findings. Plant lectins should now be added to the expanding repertoire of TLR ligands and so provide useful and versatile probes to characterize the nature of oligosaccharide surface expression and function in TLR biology.

\section{Acknowledgments}

We thank Lesley Jenkinson, Sara Botterell, Neil Fraser and Phil Shelton for their technical assistance and lain Dougall for helpful discussions. 
[1] Sharon N, Lis H. Lectins. In: William J. Lennarz, M. Encyclopedia of Biological Chemistry New York: Elsevier; 2004. p. 535-40.

[2] Sharon N, Lis H. Lectins: Cell-Agglutinating and Sugar-Specific Proteins. Science 1972;177:949 -59.

[3] Nowell PC. Phytohemagglutinin: An Initiator of Mitosis in Cultures of Normal Human Leukocytes. Cancer Res 1960;20:462-6.

[4] Kanellopoulos JM, De Petris S, Leca G, Crumpton MJ. The mitogenic lectin from Phaseolus vulgaris does not recognize the T3 antigen of human T lymphocytes. Eur J Immunol 1985;15:479-86.

[5] Hennessy EJ, Parker AE, O'Neill LAJ. Targeting Toll-like receptors: emerging therapeutics? Nat Rev Drug Discov 2010;9:293-307.

[6] Bieback K, Lien E, Klagge IM, Avota E, Schneider-Schaulies J, Duprex WP. Hemagglutinin Protein of Wild-Type Measles Virus Activates Toll-Like Receptor 2 Signaling. J Virol 2002;76:8729-36.

[7] Kammanadiminti S, Mann B, Dutil L, Chadee K. Regulation of Toll-like receptor-2 expression by the Gal-lectin of Entamoeba histolytica. FASEB J 2004;18:155-7.

[8] Byrd-Leifer C, Block E, Takeda K, Akira S, Ding A. The role of MyD88 and TLR4 in the LPS-mimetic activity of Taxol. Eur J Immunol 2001;31:2448-57.

[9] Termeer C, Benedix F, Sleeman J, Fieber C, Voith U, Ahrens T Oligosaccharides of Hyaluronan Activate Dendritic Cells via Toll-like Receptor 4. J Exp Med. 2002;195:99-111.

[10] Da Silva Correia J, Ulevitch RJ. MD-2 and TLR4 N-Linked Glycosylations Are Important for a Functional Lipopolysaccharide Receptor. J Biol Chem $2001 ; 277: 1845-54$. 
[11] Nishiya T. Ligand-regulated Chimeric Receptor Approach Reveals Distinctive Subcellular Localization and Signaling Properties of the Toll-like Receptors. J Biol Chem 2004;279:19008-17.

[12] SEAP Assay Kits. http://www.invivogen.com/family.php?|D=130 Last accessed $\left(2^{\text {nd }}\right.$ February 2011).

[13] Swartzman EE, Miraglia SJ, Mellentin-Michelotti J, Evangelista L, Yuan P. A Homogeneous and Multiplexed Immunoassay for High-Throughput Screening Using Fluorometric Microvolume Assay Technology. Anal Biochem 1999;271:143-51. [14] Cooperstock MS. Inactivation of Endotoxin by Polymyxin B. Antimicrob Agents Chemother 1974;6:422-5.

[15] Plattner VE, Wagner M, Ratzinger G, Gabor F, Wirth M. Targeted drug delivery: binding and uptake of plant lectins using human 5637 bladder cancer cells. Eur $\mathrm{J}$ Pharm Biopharm 2008;70:572-6.

[16] Debets JMH, Van der Linden CJ, Spronken IEM, Buurman WA. T Cell-Mediated Production of Tumour Necrosis Factor by Monocytes. Scand J Immunol 1988;27:601-8.

[17] Farina, C, Theil, D, Semlinger, B, Hohlfeld, R, Meinl, E.Distinct responses of monocytes to Toll-like receptor ligands and inflammatory cytokines. Int Immunol 2004;16:799-809

[18] Ferriz-Martinez RA, Torres-Artega IC, Blanco-Labra A, Garcia-Gasca T. The Role of Plant Lectins in Cancer Treatment. New Approaches in the Treatment of Cancer: Nova Science; 2010. p. 71-89.

[19] Kanellopoulosfo JM, De Petris S, Leca, G, Crumpton, MJ. The mitogenic lectin from Phaseolus vulgaris does not recognize the T3 antigen of human T lymphocytes Eur J Immunol 1985;15:479-486 
[20] Poltorak A. Defective LPS Signaling in C3H/HeJ and C57BL/10ScCr Mice:

Mutations in TIr4 Gene. Science 1998;282:2085-88.

[21] Re F, Strominger JL. Separate functional domains of human MD-2 mediate Tolllike receptor 4-binding and lipopolysaccharide responsiveness. J Immunol 2003;171:5272-6.

[22] Schumacher U, von Armansperg NG, Kreipe H, Welsch U. Lectin Binding and Uptake in Human (Myelo)monocytic Cell Lines: HL60 and U937. Ultrastruct Pathol 1996;20:463-71.

[23] Elbein AD, Solf R, Dorling PR, Vosbeck K. Swainsonine: an inhibitor of glycoprotein processing. Proc Natl Acad Sci U.S.A. 1981;78:7393-7.

[24] Berntzen G, Flo TH, Medvedev A, Kilaas L, Skjak-Brak G, Sundan A. The Tumor Necrosis Factor-Inducing Potency of Lipopolysaccharide and Uronic Acid Polymers Is Increased when They Are Covalently Linked to Particles. Clin Diagn Lab Immunol 1998;5:355-61.

[25] Majerus PW, Brodie GN. The Binding of Phytohemagglutinins to Human Platelet Plasma Membranes. J Biol Chem 1972;247:4253-7.

[26] Lis H, Sharon N. The Biochemistry of Plant Lectins (Phytohemagglutinins). Ann Rev Biochem 1973;42:541-74.

[27] Kenakin T. Functional Selectivity and Biased Receptor Signaling. J Pharmacol Exp Ther 2011;336:296-302. 
Fig. 1

Concentration-effect curves for different PHA forms, TNF $\alpha$ and LPS in

stimulating TLR4 NF-אB cell reporter activity

Assays described in Materials and Methods 2.3. Concentration effect data were fitted to a 4 parameter logistic equation to determine $\mathrm{pEC}_{50}$ and $\mathrm{IA}$.

Data points represent the mean \pm SEM $(n \geq 4)$. 


\section{Table 1}

Summary of the potency and intrinsic activity of various PHA forms in stimulating TLR4 NF-kB cell reporter activity.

Assays described in Materials and Methods 2.3.

IA values represent the maximal reporter activity as a fraction of the maximal LPS response for TLR4 or TNFa for parental cell assay. $\mathrm{pEC}_{50}$ and $\mathrm{IA}$ values represent the mean \pm SEM for the number of experiments in parentheses.

NA: Not active (IA $<0.2$ at $30 \mu \mathrm{g} / \mathrm{ml}$ for lectins and $1 \mu \mathrm{g} / \mathrm{ml}$ for $\mathrm{LPS}$ ) 


\section{Table 2}

Effect of polymyxin B on the stimulation of TLR4 NF-kB cell reporter activity by PHA-L, LPS and TNFa

Assays described in Materials and Methods 2.3. IA values represent the maximal reporter activity as a fraction of the maximal LPS response. $\mathrm{pEC}_{50}$ and IA values represent the mean \pm SEM for the number of experiments in parentheses.

$N A: I A<0.2$ at $1 \mu \mathrm{g} / \mathrm{ml}$ 


\section{Table 3}

Comparison of the effect of PHA-L and LPS on TLR4 and TLR2/6 NF-kB cell reporter activity

Assays described in Materials and Methods 2.3. IA values represent the maximal reporter activity as a fraction of the maximal LPS response for TLR4 or Pam3Cys for TLR2/6.

$\mathrm{pEC}_{50}$ and $\mathrm{IA}$ values represent the mean \pm SEM for the number of experiments in parentheses.

$N A: \mid A<0.2$ at $1 \mu \mathrm{g} / \mathrm{ml}$ 


\section{Table 4}

Comparison of how different plant lectins affect a suite of TLR NF- $k B$ cell reporter activities

Assays described in Materials and Methods 2.3. $\mathrm{pEC}_{50}$ and IA values represent the mean \pm SEM from at least three experiments. NA: Not active if $I A<0.2$ at $30 \mu \mathrm{g} / \mathrm{ml}$. IA values represent the maximal reporter activity as a fraction of the maximal LPS response for TLR4 or TNFa for parental cell assay or Pam3Cys for TLR2/6 or Poly(I:C) for TLR3, flagellin for TLR5, R848 for TLR7, 3M 002 (CL 075) for TLR8 and CpG-B for TLR9.

*TLRs located on the plasma membrane NaC-Glc: $\quad N$-acetylglucosamine

SA Sialic acid

Gal Galactose

NaC-Gal $\quad \mathrm{N}$-acetylgalactosamine

Man Mannose 


\title{
Table 5
}

\section{Effect of PHA-L on TLR8 and TLR8/4 chimera NF- $\mathrm{BB}$ cell reporter activity}

\author{
Assays described in Materials and Methods 2.3. \\ $\mathrm{pEC}_{50}$ and $\mathrm{IA}$ values represent the mean \pm SEM for the number of experiments in \\ parentheses \\ NA for 3M 002: IA $<0.05$ at $50 \mu \mathrm{M}$ \\ $\mathrm{pEC}_{50}\left(3 \mathrm{M}\right.$ 002): $-\log _{10}\left\{\mathrm{EC}_{50}[3 \mathrm{M}\right.$ 002] (M)\} \\ NA for LPS: IA $<0.2$ at $1 \mu \mathrm{g} / \mathrm{ml}$
}


Table 6

Comparison of PHA-L and LPS on TLR4 NF-KB reporter activity and TNF $\alpha$ production by human monocytes

Assays performed as in Materials and Methods 2.3

$\mathrm{pEC}_{50}$ and IA values represent the mean \pm SEM for the number of experiments in parentheses. 


\section{Table 7}

Comparison of $\mathrm{pEC}_{50}$ values for the effects of PHA-L in different assays

*Binding affinity $\left(\mathrm{K}_{\mathrm{D}}\right)$ as described in Majerus et al. [25]

\$Maximal effective concentration as described in Lis et al. [26] 


\begin{tabular}{ccccc}
\hline \multirow{2}{*}{ Ligand } & \multicolumn{2}{c}{ TLR4 } & \multicolumn{2}{c}{ Parental Cell Line } \\
\cline { 2 - 5 } & pEC $_{50}$ & IA & pEC $_{50}$ & IA \\
\hline LPS & $8.3 \pm 0.0(94)$ & 1.0 & NA (3) & \\
TNF $\alpha$ & $9.9 \pm 0.0(3)$ & $2.0 \pm 0.0(3)$ & $9.3 \pm 0.1(3)$ & 1.0 \\
PHA-P & $5.6 \pm 0.3(3)$ & $1.1 \pm 0.1(3)$ & NA (3) & \\
PHA-L & $6.1 \pm 0.3(6)$ & $0.7 \pm 0.1(6)$ & NA (3) & \\
\hline
\end{tabular}

\begin{tabular}{ccccc}
\hline \multirow{2}{*}{ Ligand } & \multicolumn{2}{c}{ TLR4 } & \multicolumn{2}{c}{ TLR4 + PMB } \\
\cline { 2 - 5 } & pEC $_{50}$ & IA & pEC & IA \\
\hline LPS & $8.0 \pm 0.0(94)$ & 1.0 & NA (4) & \\
PHA-L & $6.1 \pm 0.3(6)$ & $0.8 \pm 0.1(6)$ & $6.0 \pm 0.1(3)$ & $0.5 \pm 0.1(3)$ \\
TNFa & $10.1 \pm 0.0(3)$ & $1.7 \pm 0.0(3)$ & $10.4 \pm 0.1(4)$ & $1.3 \pm 0.1(4)$ \\
\hline
\end{tabular}

\begin{tabular}{ccccc}
\hline \multirow{2}{*}{ Ligand } & \multicolumn{2}{c}{ TLR4 } & \multicolumn{2}{c}{ TLR2/6 } \\
\cline { 2 - 5 } & $\mathrm{pEC}_{50}$ & IA & $\mathrm{pEC}_{50}$ & IA \\
\hline LPS & $8.0 \pm 0.0(94)$ & $1.0(94)$ & $\mathrm{NA}(6)$ & \\
PHA-L & $6.1 \pm 0.3(6)$ & $0.8 \pm 0.1(6)$ & $5.4 \pm 0.2(3)$ & $0.5 \pm 0.0(3)$ \\
\hline
\end{tabular}

\begin{tabular}{|c|c|c|c|c|c|c|c|c|}
\hline \multirow{2}{*}{$\begin{array}{c}\text { Lectin } \\
\text { (Recognition } \\
\text { motifs) }\end{array}$} & \multicolumn{8}{|c|}{ TLR NF-kB Reporter $p E C_{50}$ and (IA) } \\
\hline & Parental & $2 / 6^{*}$ & $4^{\star}$ & $5^{\star}$ & 3 & 7 & 8 & 9 \\
\hline $\begin{array}{l}\text { PHA-L } \\
\text { (NaC-Glc) }\end{array}$ & NA & $\begin{array}{c}5.4 \pm 0.2 \\
(0.5 \pm 0.0)\end{array}$ & $\begin{array}{l}6.1 \pm 0.3 \\
(0.7 \pm 0.0)\end{array}$ & $\begin{array}{c}4.8 \pm 0.2 \\
(0.3 \pm 0.1)\end{array}$ & NA & NA & NA & NA \\
\hline $\begin{array}{c}\text { WGA } \\
(\mathrm{NaC}-\mathrm{Gl} / \mathrm{SA})\end{array}$ & NA & $\begin{array}{c}5.7 \pm 0.1 \\
(0.5 \pm 0.0)\end{array}$ & NA & $\begin{array}{c}5.7 \pm 0.5 \\
(0.6 \pm 0.0)\end{array}$ & NA & $\begin{array}{c}6.0 \pm 0.2 \\
(0.2 \pm 0.0)\end{array}$ & $\begin{array}{c}6.2 \pm 0.1 \\
(0.7 \pm 0.1)\end{array}$ & $\begin{array}{c}5.6 \pm 0.1 \\
(0.5 \pm 0.1)\end{array}$ \\
\hline $\begin{array}{c}\text { SBA } \\
\begin{array}{c}\text { (Gal/Gal/NaC- } \\
\text { Gal) }\end{array}\end{array}$ & NA & NA & $\begin{array}{c}5.4 \pm 0.5 \\
(1.4 \pm 0.0)\end{array}$ & NA & NA & NA & NA & NA \\
\hline $\begin{array}{c}\text { PNA } \\
\text { (Gal/NaC-Gal) }\end{array}$ & NA & NA & $\begin{array}{c}5.3 \pm 0.3 \\
(1.2 \pm 0.3)\end{array}$ & NA & NA & NA & NA & NA \\
\hline $\begin{array}{c}\text { AlL } \\
\text { (Gal/NaC-Gal) }\end{array}$ & NA & NA & NA & NA & NA & NA & NA & NA \\
\hline $\begin{array}{c}\text { ConA } \\
\text { (Glc/Man) }\end{array}$ & NA & $\begin{array}{c}5.4 \pm 0.0 \\
(0.3 \pm 0.0)\end{array}$ & NA & NA & NA & NA & NA & NA \\
\hline
\end{tabular}




\begin{tabular}{ccccccc}
\hline \multirow{2}{*}{ Ligand } & \multicolumn{2}{c}{ TLR4 } & \multicolumn{2}{c}{ TLR8 } & \multicolumn{2}{c}{ TLR8/4 } \\
\cline { 2 - 6 } & pEC $_{50}$ & IA & pEC $_{50}$ & IA & pEC $_{50}$ & IA \\
\hline LPS & $8.0 \pm 0.0(94)$ & $1.0(94)$ & NA (4) & & NA (5) & \\
PHA-L & $6.1 \pm 0.3(6)$ & $0.7 \pm 0.1(6)$ & NA (4) & & NA (3) & \\
3M 002 & NA (5) & & $5.9 \pm 0.2(6)$ & $1(6)$ & $5.9 \pm 0.3(3)$ & $1.0(3)$ \\
\hline
\end{tabular}

\begin{tabular}{ccccc}
\hline \multirow{2}{*}{ Ligand } & \multicolumn{2}{c}{$\begin{array}{c}\text { TLR4 NF-kB reporter } \\
\text { activity }\end{array}$} & \multicolumn{2}{c}{$\begin{array}{c}\text { Production of TNFa by } \\
\text { Monocytes }\end{array}$} \\
\cline { 2 - 5 } & pEC $_{50}$ & IA & pEC $_{50}$ & IA \\
\hline LPS & $8.0 \pm 0.0(94)$ & 1.0 & $10.0 \pm 0.1(3)$ & $1.0 \pm 0.1(3)$ \\
PHA-L & $6.1 \pm 0.3(6)$ & $0.7 \pm 0.1(6)$ & $4.6 \pm 0.1(3)$ & $0.2 \pm 0.06(3)$ \\
\hline
\end{tabular}

\begin{tabular}{|c|c|c|c|c|}
\hline \multirow[t]{2}{*}{ Lectin } & $\begin{array}{c}\text { hrTLR4 } \\
\text { Agonism }\end{array}$ & Binding ${ }^{*}$ & $\begin{array}{c}\text { PBMC } \\
\begin{array}{c}\text { Stimulation } \\
\text { (Maximal effective } \\
\text { concentration) }\end{array} \\
\end{array}$ & $\begin{array}{l}\text { Monocyte } \\
\text { TNFa }\end{array}$ \\
\hline & & & $\mathrm{C}_{50}$ & \\
\hline PHA-L & 6.1 & 5.5 & $5.5-6$ & 4.6 \\
\hline
\end{tabular}




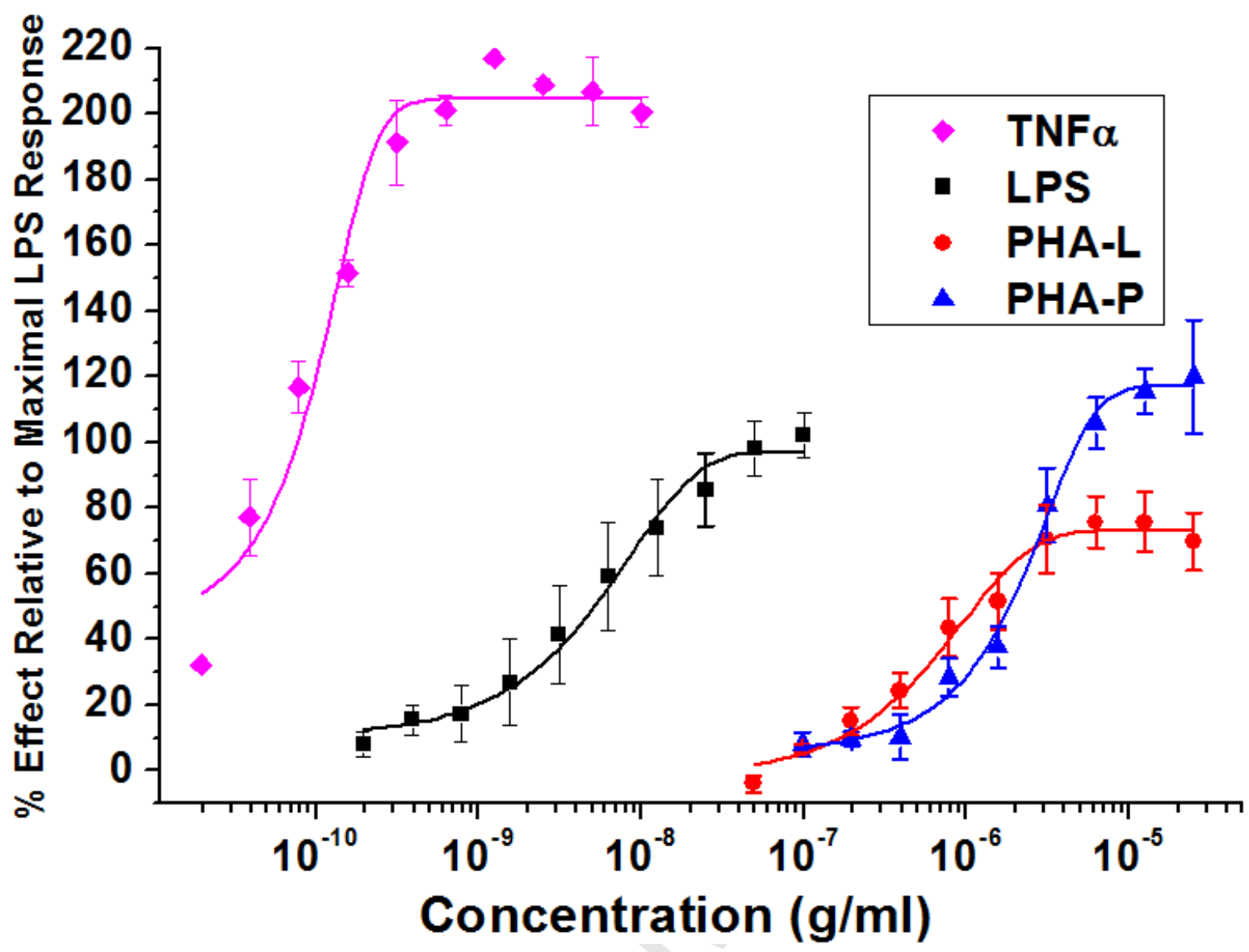




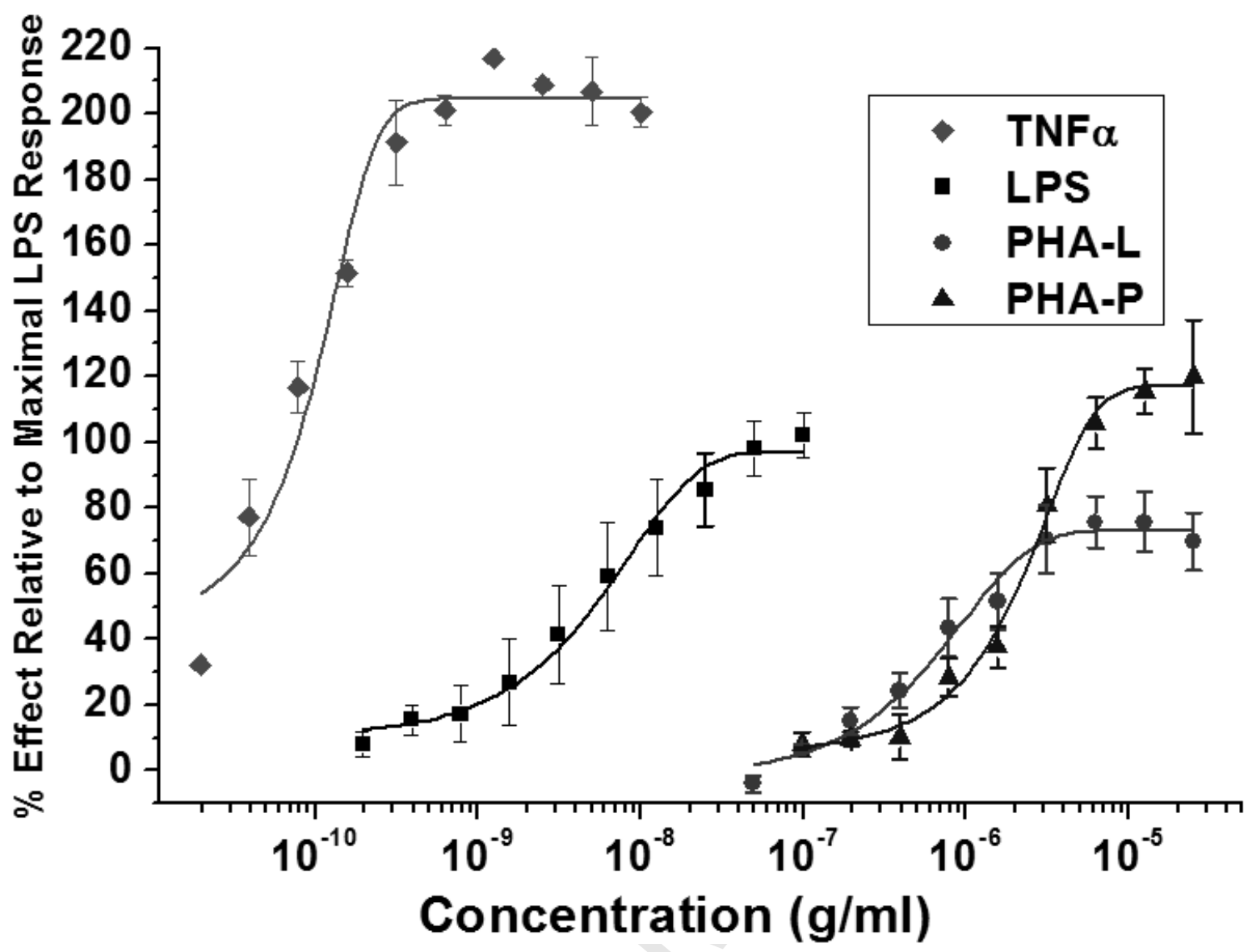




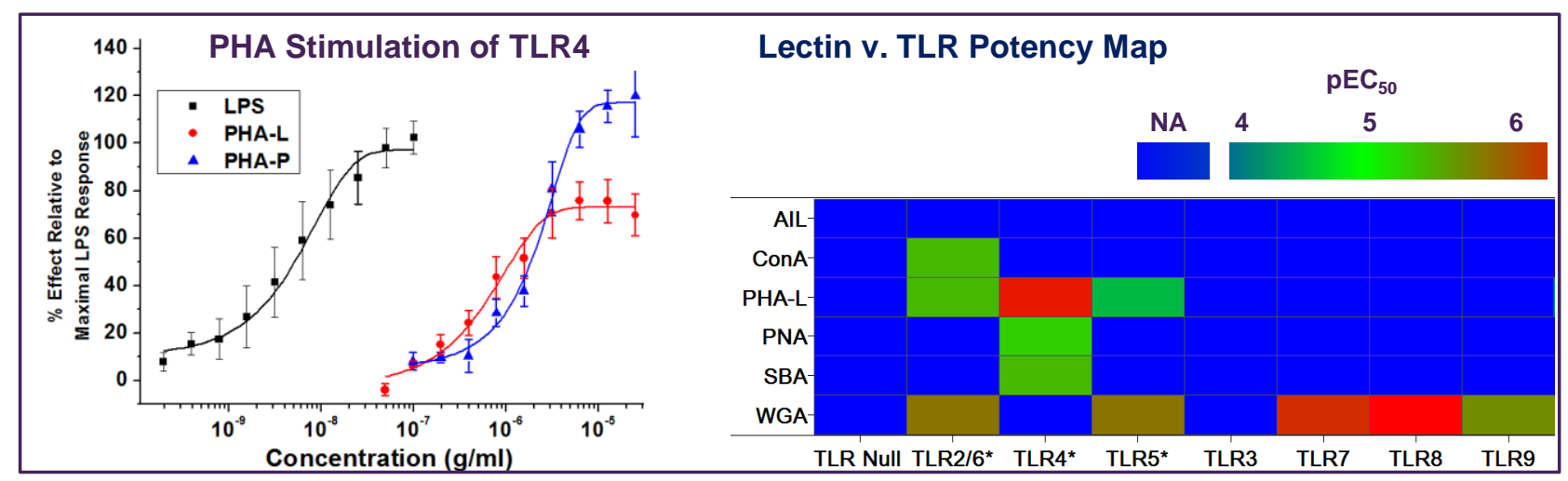

AstraZeneca 2 


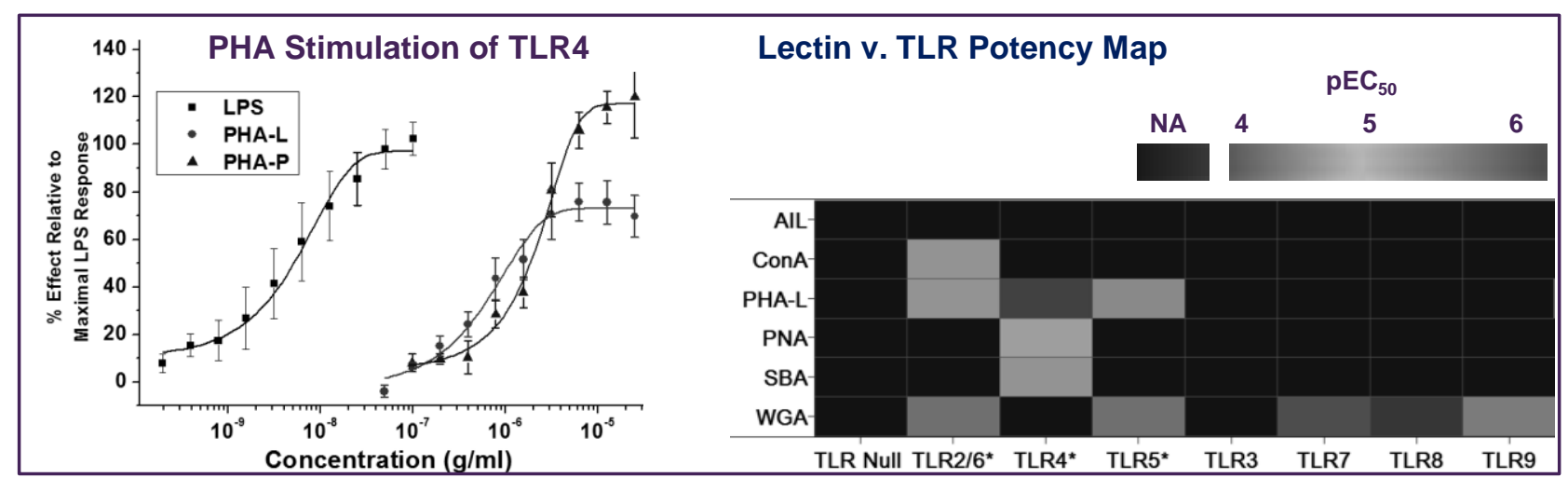

AstraZeneca 2 